\title{
Eelectrochemical Detection of Methyl Parathion in Fritillaria thunbergii Based on Acetylcholinesterase Immobilized Gold Nanoshpere
}

\author{
Jianwei Jiang, Hongyan Zhang, Chunlei Wang ${ }^{*}$ and Ying Xu
}

The Department of Pharmacy, Zhejiang Cancer Hospital, 38 Guangji Rd, Gongshu, Hangzhou, Zhejiang, 310022, P.R. China

*E-mail: chunleiwang_zch@yeah.net

doi: $10.20964 / 2016.07 .31$

Received: 1 April 2016 / Accepted: 19 May 2016 / Published: 4 June 2016

Large use of pesticide is an important issue in modern agriculture. Development of a reliable analytical method for pesticide detection in essential for many fields. In this work, we proposed an electrochemical based detection method for methyl parathion, an organophosphate pesticide, residue in the Fritillaria thunbergii, a medicinal plant has been cultivated for several thousand years, based on the acetylcholinesterase immobilized gold nanoshpere (Au NS) modified electrode. The combination of acetylcholinesterase and Au NS displayed a strong synergetic effect on enhancing the detection properties of methyl parathion. Au NS could catalyze the oxidation process of the enzymatically produced thiocholine and result a high sensitivity. After optimization, the proposed biosensor was used for analyzing the methyl parathion residue in freshly harvested Fritillaria thunbergii.

Keywords: Pesticide; Methyl parathion; Fritillaria thunbergii; Gold nanoshpere; Acetylcholinesterase

\section{$\underline{\text { FULL TEXT }}$}

(C) 2016 The Authors. Published by ESG (www.electrochemsci.org). This article is an open access article distributed under the terms and conditions of the Creative Commons Attribution license (http://creativecommons.org/licenses/by/4.0/). 